www.jmscr.igmpublication.org Impact Factor 5.244

Index Copernicus Value: 83.27 ISSN (e)-2347-176x ISSN (p) 2455-0450 crossref DOI: _https://dx.doi.org/10.18535/jmscr/v4i11.28

\title{
An Observational Study of Incidence and Pattern of Surgical Site Infections in Emergency Surgeries
}

\author{
Authors \\ Hem Chander Pandey ${ }^{1}$, R Venkatnarayanan ${ }^{2}$, Naveen Kumar ${ }^{3}$, Anand Munghate ${ }^{4}$ \\ ${ }^{1}$ MS (Surgery), Surgeon, Working in Armed Forces, India \\ ${ }^{2} \mathrm{MS}, \mathrm{MCh}$, Surgeon, Working in Armed Forces, India \\ Email:drsharma1212@gmail.com \\ ${ }^{3}$ MS (Surgery), Senior Resident, Department of Surgery, Sharda University, Greater Noida (India) \\ Email: naveen041988@gmail.com \\ ${ }^{4}$ MS (Surgery), Senior Resident, Department of Surgery, Safdarjang Hospital, Delhi (India) \\ Email:dr.anand24by7@yahoo.com \\ Corresponding Author \\ Hem Chander Pandey \\ S-63 A, Pandav Nagar, Near Mother Dairy, Delhi-110092 \\ Email: pandeyhc.delhi@gmail.com,Mob;09599927775
}

\begin{abstract}
Background- Surgical Site Infections (SSIs) result from bacterial contamination during or after a surgical procedure. The risk of infection is greater in all categories if surgery is performed as an emergency. SSI causes considerable morbidity, mortality and high cost to the health care system and is becoming increasingly important in medicolegal aspects.

Material \& Methods- An observational study was conducted over a period from Jan 2013 to Jun 2014 at Command Hospital (EC), Kolkata (India). Patients requiring emergency surgery and fulfilling the inclusion criteria were offered to participate in the study. Total 108 cases undergoing emergency operations in all disciplines were included. Various parameters studied were as follows - Incidence of surgical site infection, correlation with age, sex, comorbidity status, malnutrition, delay to initiate operation, operative time, degree of contamination.

Results- A statistically significant association was found between SSI and comorbidity, malnutrition, delay in operation, operative time and degree of contamination.

Conclusion- Proper care of the patients as a whole throughout perioperative period is very vital to reduce the rate of SSI. Identification of factors that increase the risk for SSIs following surgery is a key step in the reduction of morbidity and mortality.

Keywords - Emergency, Surgery, Surgical site infections.
\end{abstract}

\section{INTRODUCTION}

The surgical site is the second or third mostcommon site of all nosocomial infections, with infections of the urinary tract being the most- common. ${ }^{1}$ Among surgical patients, SSIs account for $38 \%$ of all nosocomial infections. ${ }^{2}$ Infections in the area of operational wound within 30 days of operation, confirmed by microbiological examina- 
tion were regarded as SSI. ${ }^{3}$ The development of a SSI can be multicausal, but the necessary cause is damage to host barrier mechanisms induced by the trauma of a surgical incision. The risk of infection is greater in all categories if surgery is performed as an emergency. ${ }^{4}$ Multiple risk factors and perioperative characteristics can increase the likelihood of SSIs. Identification of factors that increase the risk for SSIs following surgery is a key step in the reduction of morbidity and mortality. Keeping this in mind, this observational study was undertaken to elucidate the extent of the problem and to ascertain the risk factors involved.

\section{MATERIAL AND METHODS}

We conducted an observational study over a period from Jan 2013 to Jun 2014 at Command Hospital (EC), Kolkata. Total 108 cases undergoing emergency operations in all disciplenes of Surgery including General Surgery, Gastrointestinal Surgery, Neurosurgery, Plastic Surgery, Orthopedic Surgery etc were included. All the traumatic cases with open wounds and redo surgeries on patients transferred from other hospitals as well as those operated after $48 \mathrm{~h}$ of admission were excluded from the study.
Informed written consent was taken from the patients or their guardian willing to participate in the study. History was taken and thorough physical examination was conducted on each patient. Various parameters studied were as follows - Incidence of surgical site infection, correlation with age, sex, comorbidity status, malnutrition, delay to initiate operation if any, operative time, degree of contamination. Detailed history was taken to know about the presence of the risk factors regarding SSI. Strict aseptic precautions were followed during the operation. During the postoperative period all the patients were closely monitored everyday up to the discharge of the patient from the hospital. If any symptom or sign of infection appeared during this period then proper investigation was instituted for the diagnosis of infection and to assess its type and severity.

\section{RESULTS}

Collected data was arranged in systematic manner, presented in various tables and figures and statistical analysis was made using Chi square test.

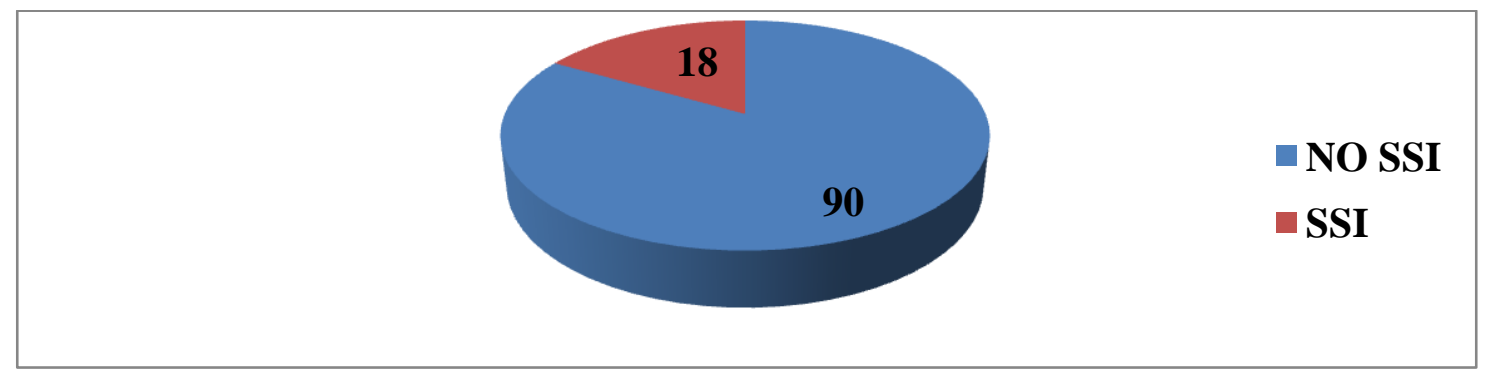

Figure I: PIE Diagram Showing Incidence of SSI

Out of the 108 patients, 18 got infected postoperatively amounting to a total of $16.67 \%$ incidence of SSI.

(Fig.I)

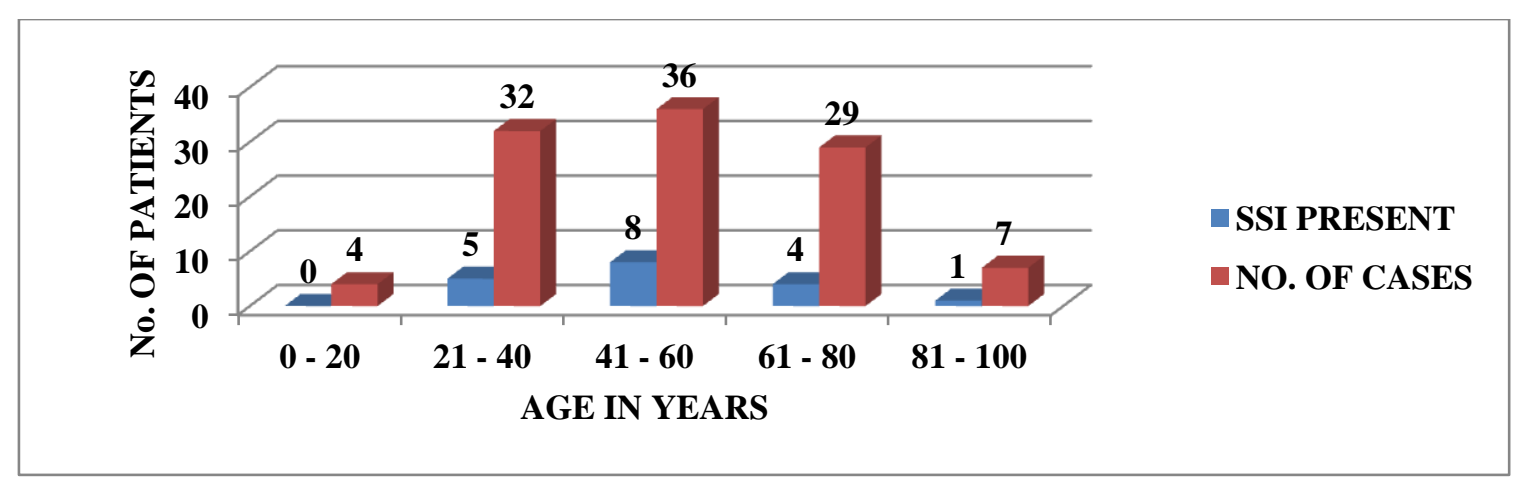

Figure II: SSI Distribution by Age 


\section{JMSCR Vol||04||Issue||11||Page 13686-13691||November}

The SSI percentage in different age groups ranged from $0 \%$ in age group $0-20$ years, $15.63 \%$ in age group $21-40$ years, $22.22 \%$ in age group 41 - 60 years, $13.79 \%$ in age group $61-80$ years and $14.29 \%$ in age group $81-100$ years. (Fig.II) The statistical analysis of the data $[\chi 2=1.831$, $\mathrm{p}<0.975>0.20, \mathrm{df}=4]$ however, did not reveal any significant association between SSI and age.

In the study of effect of sex on SSI, it was observed that among 81 males, $12(14.81 \%)$ developed SSI, whereas among 27 females, 06 $(22.22 \%)$ developed SSI. (Fig.III) Incidence of SSI was found to be higher in females than in males, suggesting that sex of the patient may predispose the patient to a higher risk of SSI. Statistics revealed that it is unlikely to be a strong association, between sex and SSI, $\left[\chi^{2}=0.804, \mathrm{p}=<\right.$ 0.90].

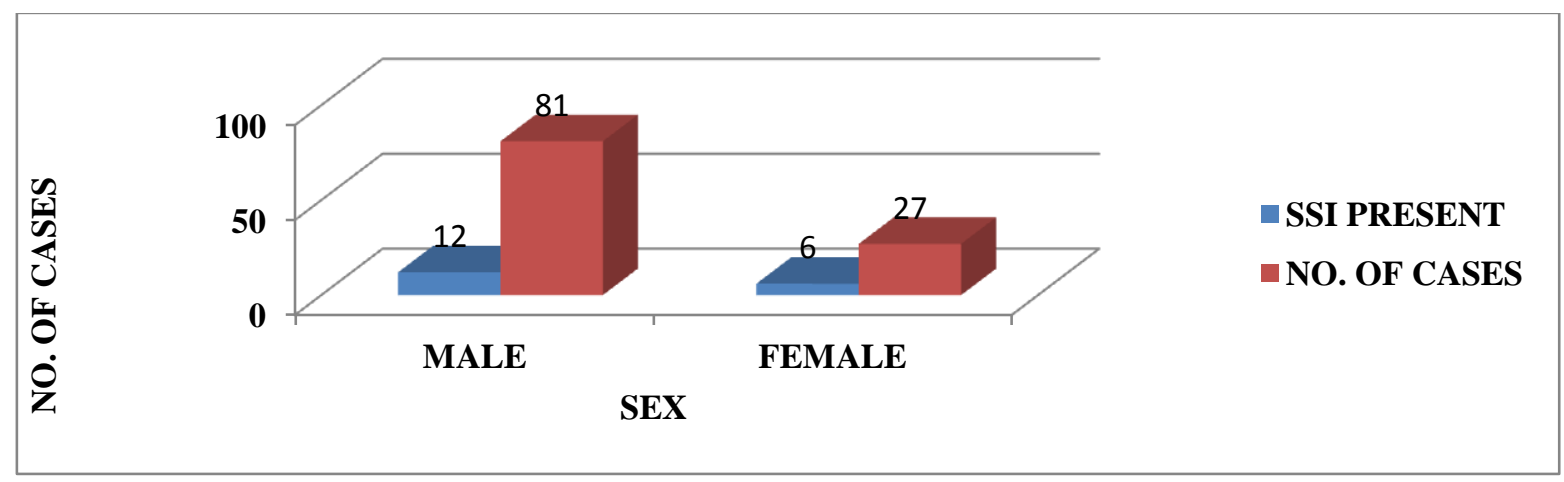

Figure III: SSI In Relation To Gender

Table I: Surgical Site Infection Distribution by Comorbidity

\begin{tabular}{|c|c|c|c|c|c|c|c|}
\hline \multirow{2}{*}{ COMORBIDITY } & \multicolumn{2}{|c|}{ SSI } & \multirow[t]{2}{*}{$\begin{array}{l}\text { TOTAL } \\
\text { NO. }\end{array}$} & \multirow{2}{*}{$\begin{array}{l}\text { DIABETES } \\
\text { MELLITUS }\end{array}$} & \multicolumn{2}{|c|}{ SSI } & \multirow{2}{*}{$\begin{array}{c}\text { TOTAL } \\
\text { NO. }\end{array}$} \\
\hline & YES (\%) & NO (\%) & & & YES(\%) & $\mathrm{NO}(\%)$ & \\
\hline PRESENT & 34.29 & 65.71 & 35 & PRESENT & 50 & 50 & 8 \\
\hline ABSENT & 8.22 & 91.78 & 73 & ABSENT & 10.34 & 89.66 & 87 \\
\hline TOTAL & 16.67 & 83.3 & 108 & TOTAL & 13.68 & 86.32 & 95 \\
\hline
\end{tabular}

It was observed that among the patients with comorbid disorders, 12 (34.29\%) developed SSI, whereas in patients without any comorbidity, 6 $(8.22 \%)$ developed SSI. The data suggested strong influence of comorbidity on SSI $\left[\chi^{2}=11.01\right.$, $\mathrm{p}<0.005, \mathrm{df}=1]$. Out of 21 diabetic patients, $8 \mathrm{had}$ only DM as a single comorbidity. Among these 8 patients, SSI developed in 4 patients (50\%). Among 87 non diabetics, only 9 patients (10.34\%) developed SSI. (Tab.I) The data suggested strong influence of Diabetes Mellitus on SSI $\left[\chi^{2}=9.75\right.$, $p$ $<0.005, \mathrm{df}=1]$.
Malnutrition can have a profound effect on the general health and ability of an individual and therefore it was observed if it could also affect postoperative SSI development. It was observed that only 6 patients $(5.56 \%)$ out of the total 108 patients employed in the present study were malnourished. Fifty percent of these cases developed SSI. (Fig.IV) The connection between malnutrition and SSI was statistically significant $\left[\chi^{2}=5.487, \mathrm{p}<0.025, \mathrm{df}=1\right]$ 


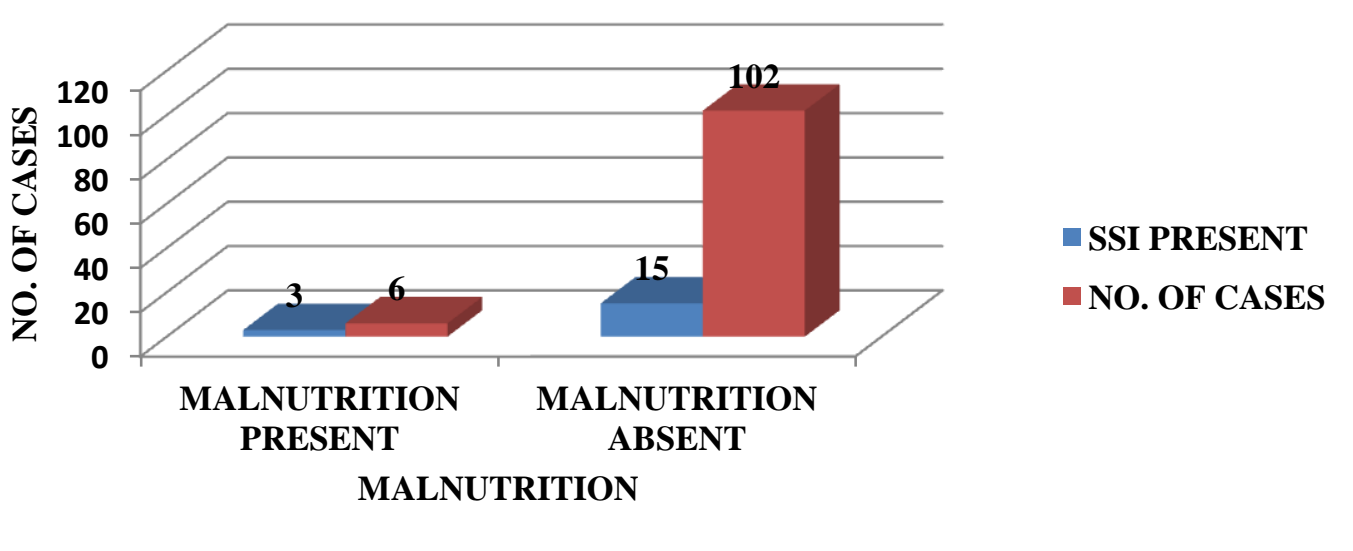

Figure IV: SSI in Relation to Malnutrition

Table II: SSI Distribution Based on Duration of Operation \& Delay to Initiate Operation

\begin{tabular}{|c|c|c|c|c|c|c|c|}
\hline \multirow{2}{*}{$\begin{array}{l}\text { DURATION OF } \\
\text { OPERATION }\end{array}$} & \multicolumn{2}{|c|}{ SSI } & \multirow[t]{2}{*}{$\begin{array}{c}\text { TOTAL } \\
\text { NO. }\end{array}$} & \multirow{2}{*}{$\begin{array}{c}\text { DELAY TO } \\
\text { INITIATE } \\
\text { OPERATION ( HRS) }\end{array}$} & \multicolumn{2}{|c|}{ SSI } & \multirow{2}{*}{$\begin{array}{c}\text { TOTAL } \\
\text { NO. }\end{array}$} \\
\hline & YES (\%) & NO (\%) & & & YES (\%) & $\mathrm{NO}(\%)$ & \\
\hline$\leq 1 \mathrm{H}$ & 0 & 100 & 29 & $\leq 12 \mathrm{H}$ & 4.44 & 95.56 & 45 \\
\hline$>1 \mathrm{H} \mathrm{TO} \leq 2 \mathrm{H}$ & 6.45 & 93.55 & 31 & $>12 \mathrm{H}-\leq 24 \mathrm{H}$ & 15.15 & 84.85 & 33 \\
\hline$>2 \mathrm{H} \mathrm{TO} \leq 3 \mathrm{H}$ & 9.09 & 90.91 & 22 & $>24 \mathrm{H}-\leq 48 \mathrm{H}$ & 27.78 & 72.22 & 18 \\
\hline$>3 \mathrm{H} \mathrm{TO} \leq 4 \mathrm{H}$ & 64.29 & 35.71 & 14 & $>48 \mathrm{H}$ & 50 & 50 & 12 \\
\hline$>4 \mathrm{H}$ & 41.67 & 58.33 & 12 & TOTAL & 16.67 & 83.33 & 108 \\
\hline TOTAL & 16.67 & 83.33 & & & & & \\
\hline
\end{tabular}

The results showed a steady increase in incidence of SSI with increase in the duration of surgery with the highest observed value in the time interval $>3 \mathrm{~h}$ to $\leq 4 \mathrm{~h}$. There seems to be a strong correlation between the duration of surgery and the incidence of SSI with a p-value $<0.005$ $\left[\chi^{2}=37.237, \mathrm{p}<0.005, \mathrm{df}=4\right]$. However, it was noted that when surgery exceeded $4 \mathrm{~h}$ duration, SSI development fell down by a small margin to $41.67 \%$. The studies with the present data set were extended to investigate the effect of delay in surgery on SSI development. As can be clearly seen, the incidence of infection sufficiently increased as the time lapse between appearance of first symptom and initiation of operation increased. The results were significant and suggested that delay in initiation of surgery can greatly affect SSI development. $\left[\chi^{2}=16.067\right.$, $\mathrm{p}<0.005]$. (Tab.II)

Table III: SSI Distribution Based on Type of Wound by the Degree of Contamination

\begin{tabular}{|l|c|c|c|}
\hline TYPE OF WOUND & \multicolumn{2}{|c|}{ SSI } & TOTAL NO. \\
\hline & YES (\%) & NO $(\%)$ & \\
\hline CLEAN & 2.63 & 97.37 & 38 \\
\hline CLEAN CONTAMINATED & 3.70 & 96.30 & 27 \\
\hline CONTAMINATED & 25.93 & 74.07 & 27 \\
\hline DIRTY & 56.25 & 43.75 & 16 \\
\hline TOTAL & $\mathbf{1 6 . 6 7}$ & $\mathbf{8 3 . 3 3}$ & $\mathbf{1 0 8}$ \\
\hline
\end{tabular}

With respect to types of wounds studied by the degree of contamination for SSI development, it was observed that in both 38 clean wounds and 27 clean contaminated wounds, only 1 in each category developed SSI giving an SSI percentage of $2.63 \%$ and $3.70 \%$ respectively. However, $25.93 \%$ of contaminated wounds ( 7 out of 27 ) and
$56.25 \%$ of dirty wounds (9 out of 16 cases), developed SSI. The p-value for the association of type of wound to SSI was $<0.005$, suggesting a very strong connection between the two $\left[\chi^{2}=28.327, \mathrm{p}<0.005, \mathrm{df}=3\right]$. (Tab.III) 


\section{DISCUSSION}

The study was carried out with a view to determine the factors responsible for surgical site infections (SSI) following emergency operations in patients with conditions other than trauma. The long term goal was to reduce the incidence of SSI in these patients. Infection rate increases when surgery is done in an emergency. The high rates of infection in emergency surgeries may be because of insufficient pre-operative preparation, the underlying conditions which predisposed to the emergency surgery and more frequency of contaminated or dirty wounds in emergency surgeries. ${ }^{5}$

The SSI percentage in different age groups ranged from $0 \%$ in age group $0-20$ years, $15.63 \%$ in age group $21-40$ years, $22.22 \%$ in age group 41 - 60 years, $13.79 \%$ in age group $61-80$ years and $14.29 \%$ in age group $81-100$ years. The higher incidence of SSI in older patients is perhaps due to decreased immunocompetence \& higher chances of comorbid conditions. ${ }^{6}$ In this study, the statistical analysis of the data however, did not reveal any significant association between SSI and age probably because of uneven distribution of patients in different age groups and because of small sample size. A further study with a larger sample size may reveal different association between the parameters.

Incidence of SSI was found to be higher in females than in males, suggesting that sex of the patient may predispose the patient to a higher risk of SSI. Statistics revealed that it is unlikely to be a strong association, between sex and SSI, suggesting that sex of the patient is unlikely to affect postoperative SSI and that the values obtained in the present study are likely to be a chance event. Higher incidence of SSI in females observed in present study may be due to smaller sample size of female patients (Male:Female ratio being $3: 1$ ). This is also likely due to the limited number of total patients in the study. A study designed with a higher patient number is required to ascertain this.

Effect of comorbidities were also studied on the same set of patients and it was observed that 35 patients $(32.41 \%)$ had some form of comorbid disorders along with the surgical disease while 73 patients had no comorbid disorders. The data suggested statistically strong influence of comorbidity on SSI including a significant relationship between Diabetes Mellitus and SSI. It was clear that associated co-morbid disorders played a vital role as a host related risk factor for SSI. High blood sugar can increase infection rate and impair wound healing. Possible etiologies may be because of diabetic microangiopathy, diabetic neuropathy, increased glycosylated haemoglobin in diabetics which decreases the oxygen dissociation, increased glycosylated tissue protein which decreases the oxygen utilization. Poorly controlled diabetes adversely affects the ability of leukocytes to destroy invading bacteria and to prevent the harmful proliferation of usually benign bacteria present in the healthy body. ${ }^{7}$

Malnutrition can have a profound effect on the general health and ability of an individual and therefore it was observed if it could also affect postoperative SSI development. Nutritional deficiencies are associated with poor immune response to infection. Malnutrition can make a person more susceptible to infection, and infection also contributes to malnutrition, which causes a vicious cycle. An inadequate dietary intake leads to weight loss, lowered immunity, mucosal damage, invasion by pathogens, and impaired growth and development. ${ }^{8}$

With respect to the duration of operation and incidence of SSI, results showed a steady increase in incidence of SSI with increase in the duration of surgery with the highest observed value in the time interval $>3 \mathrm{~h}$ to $\leq 4 \mathrm{~h}$. There seems to be a strong correlation between the duration of surgery and the incidence of SSI with a p-value $<0.005$. It may be due to the prolonged exposure of the wound to the environment leading to more chance to inoculation of micro-organisms. ${ }^{9}$ Fall in SSI observed in surgeries lasting > $4 \mathrm{~h}$ may be because most of surgeries requiring this much period of time are neurosurgical, which in themselves have low SSI rates. The marginal drop in SSI percentage in cases requiring $>4 \mathrm{~h}$ surgery 
could also be easily explained as an outlier observation due to limited number of case studies available.

The studies with the present data set were also extended to investigate the effect of delay in surgery on SSI development. The results revealed that the incidence of infection sufficiently increased as the time lapse between appearance of first symptom and initiation of operation increased.

With respect to type of wound studied by the degree of contamination for SSI development, a very strong connection was observed between the two. The difference in the rates of SSIs between the clean and the clean contaminated wounds showed the effect of endogenous contamination and the difference in the rates of SSIs between the clean contaminated and the dirty wounds showed the effect of exogenous contamination. The endogenous or the exogenous contamination of the wounds by the organisms had a profound influence on the SSIs. ${ }^{10}$

\section{CONCLUSION}

Proper care of the patients as a whole throughout perioperative period is very vital to reduce the rate of SSI. Prompt diagnosis, proper assessment, quick resuscitation and appropriate preoperative preparation are keys to better outcome in emergency operations.

NO CONFLICTS OF INTEREST EXISTS; NO FINANCIAL DISCLOSURE

\section{REFERENCES}

1. Lilani SP, Jangale N, Chowdhary A, Devar GB. Surgical site infections in clean and clean-contaminated cases. Indian $\mathrm{J}$ Med Microbiol 2005; 23(4):249-52.

2. Spagnolo AM, Ottria G, Amicizia D, Perdelli F, Cristina ML. Operating theatre quality and prevention of surgical site infections. J Prev Med Hyg. 2013; 54(3): 131-7.
3. Bharathidasan R, Jayaprakas R, Ambujam G. Surgeons nightmare-wound infection following abdominal operations-our experience. Asia Pacific Journal of Research. 2016; 2: 40-5.

4. Kirk R.M., Ribbans, W.J., 2004. Clinical surgery in general (RCS course manual), 4th ed. Churchill livingstone, London, UK; 206-382.

5. Satyanarayana V et al. Study of Surgical Site Infections in Abdominal Surgeries. Journal of Clinical and Diagnostic Research; 2011; 5(5): 935-9.

6. Trebse R. Infected total joint arthroplasty : The algorithmic approach, 2012 edition. Springer Science \& Business Media; 77.

7. Alsaimary I. Bacterial Wound Infections in Diabetic Patients and Their Therapeutic Implications. The Internet Journal of Microbiology. 2008; 7: 1-5.

8. Katone $\mathrm{P}$, Apte JK. The interaction between nutrition and infection, Clin Infect Dis 2008; 46(10): 1582-8.

9. Filbert J Mpogoro, Stephen E Mshana, Mariam M Mirambo, Benson R Kidenya, Balthazar Gumodoka, Can Imirzalioglu' Incidence and predictors of surgical site infections following caesarean sections at Bugando Medical Centre, Mwanza, Tanzania. Antimicrob Resist Infect Control. 2014; 3: 25.

10. Mahesh C B, Shivakumar S, Suresh B S, Chidanand S P, Vishwanath Y. A Prospective Study Of Surgical Site Infections In A Teaching Hospital. 2010; 4(5): $3114-9$. 